\title{
Synthesis of Chiral Helical Chromophore-functionalized Polybinaphthalenes
}

Guy Koeckelberghs ${ }^{1}$, Leen De Groof ${ }^{1}$, Sonja Sioncke ${ }^{2}$, Thierry Verbiest ${ }^{2}$, André Persoons ${ }^{2}$, Celest Samyn ${ }^{1 *}$

${ }^{1}$ Laboratory of Macromolecular and Physical Organic Chemistry, Katholieke Universiteit Leuven, Celestijnenlaan 200F, B-3001 Heverlee, Belgium

${ }^{2}$ Laboratory of Chemical and Biological Dynamics, Katholieke Universiteit Leuven, Celestijnenlaan 200D, B-3001 Heverlee, Belgium

Fax: +32(0) 16327990

Tel: $+32(0) 16327438$

E-mail:celest.samyn@chem.kuleuven.ac.be

\section{Summary}

Chromophore-functionalized, chiral, helical polybinaphthalenes with acetylene linkage have been prepared by functionalization of precursor polymers. The chromophores seem to be chirally ordered in these materials. This property, and the large possibilities for architectural diversification, make these materials promising candidates for nonlinear optical studies as well as applications thereof.

Keywords: polybinaphthalenes, nonlinear polymers, chiral 


\section{Introduction}

During several years, chromophore-functionalized polymer systems have been intensively studied for their nonlinear optical (NLO) properties. This has led to the development of a large number of new chromophores with moderate to superb hyperpolarizabilities. Since polymers show additional advantages compared to their inorganic analogues, s.a. good processability, low dielectric constant, large architectural diversification as well as a high laser damage threshold, polymer materials that contain NLO active chromophores, seem to be very promising for NLO studies. Most polymers so far investigated adapt a random coil conformation. Only a few examples of helical, rod-like polymer systems have been studied as NLO materials so far, although they may be interesting NLO candidates. ${ }^{[1]}$ When incorporated as side-chains, the chromophores can easily be poled, like in random coil-like systems. But, since the chromophores are attached to a rigid, non bendable backbone, the undesired dipolar interactions will be largely reduced in these systems. Moreover, if chiral helical polymers are used, these systems can benefit from the chirality of the sample. The use of chirality in second-order nonlinear optics has been thoroughly investigated. ${ }^{[2]}$ These studies have demonstrated that chirality can relax the requirement for a polar ordering. Moreover, chiral contributions can increase the NLO response.

In this paper, we report the synthesis of chiral, helical chromophore-functionalized polybinaphthalenes. Polybinaphthalenes were chosen as polymer system, since these polymers are helical (if appropriately designed) and chiral systems can easily be obtained by polymerizing chiral binaphthalene monomers. Moreover, these materials exhibit an excellent thermal, chemical and photochemical stability. The chromophores were incorporated as side chains, to enhance solubility, film forming properties and synthetical diversification. The polymers were prepared in a two-step process, since the chromophores degrade under the 
reaction conditions for polymerisation. ${ }^{*}$ In a first step, precursor polymers were prepared by a Sonogashira reaction between chiral diethynyl binaphthalene monomers and a diiodo compound. In a second step, chromophores are linked to the polymer backbone by reaction with chromophores under Mitsunobu conditions. In this way, this new class of chiral chromphore-functionalised polymer materials were made accessible.

\section{Experimental part}

\section{Materials}

All starting materials were purchased from Acros Organics, Fluka, Merck or Aldrich and were used as received. Tetrahydrofuran (THF) was dried over a $\mathrm{Na} / \mathrm{K}$ alloy and $N, N$ -

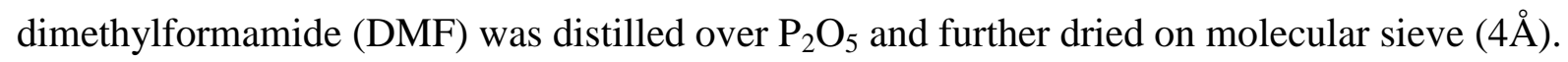
1, 7 and the chromophores $\mathbf{B}, \mathbf{C}$ and $\mathbf{D}$ were synthesized according to literature procedures. ${ }^{[3 \mathrm{a}-}$ c] $\mathbf{A}$ is a commercial product. Synthesis of (S)-(+)-6,6'-diethynyl-[1,1'-binaphthalene]-2,2'-diol $3^{[1 \mathrm{e}-\mathrm{f}, 4]}$ (S)-6,6'-di(trimethylsilylethynyl)-[1,1'-binaphthalene]-2,2'-diol 2

Prior to use, 1 was recrystallized from toluene/hexane. 1 (11.1 g, $25.0 \mathrm{mmol}), \mathrm{Pd}\left[\mathrm{PPh}_{3}\right]_{2} \mathrm{Cl}_{2}$ (250 mg) and $\mathrm{PPh}_{3}(500 \mathrm{mg})$ were dissolved in dry piperidine $(50 \mathrm{ml})$. The solution was purged with argon and heated to $40{ }^{\circ} \mathrm{C}$. To this solution, trimethylsilylacetylene $(9.9 \mathrm{ml}, 70.0$ mmol) was injected, followed by an argon purged solution of $\mathrm{CuI}(200 \mathrm{mg})$ and $\mathrm{LiBr}(1000$ $\mathrm{mg})$ in dry THF (10 ml). The reaction mixture was refluxed for one hour under argon atmosphere. After cooling, the mixture was poured into a $\mathrm{HCl}$-solution $(400 \mathrm{ml}, 1 \mathrm{M})$ and extracted with dichloromethane. The combined organic layers were washed with a HClsolution $(1 \mathrm{M})$, with a saturated $\mathrm{NaHCO}_{3}$-solution, with brine and finally dried over $\mathrm{MgSO}_{4}$. The solvents were removed and the crude product was purified by column chromatography

\footnotetext{
${ }^{*}$ Every attempt we tried to polymerize chromophore-functionalized monomers using a Sonogashira reaction has led to chromophore degradation.
} 
(silicagel; eluent: ethylacetate/dichloromethane $(30: 70 \mathrm{v} / \mathrm{v}))$. The product was isolated as an oil and used without further purification in the next step.

${ }^{1} \mathrm{H}-\mathrm{NMR}\left(\mathrm{CDCl}_{3}\right): \quad \delta=8.02(\mathrm{~d}, \mathrm{~J}=1.5 \mathrm{~Hz}, 2 \mathrm{H}), 7.88(\mathrm{~d}, 2 \mathrm{H}), 7.34(\mathrm{~d}, 2 \mathrm{H}), 7.29(\mathrm{dd}, 2 \mathrm{H})$, $6.98(\mathrm{~d}, 2 \mathrm{H}), 5.05(\mathrm{~s}, 2 \mathrm{H}), 0.24(\mathrm{~s}, 18 \mathrm{H})$.

(S)-(+)-6,6'-diethynyl-[1,1'-binaphthalene]-2,2'-diol 3

A solution of 2 in methanol $(70 \mathrm{ml})$ and THF $(30 \mathrm{ml})$ was purged with argon and treated with a $\mathrm{NaOH}$-solution $(25 \mathrm{ml}, 2 \mathrm{M})$. The mixture was vigorously stirred for one hour at $40{ }^{\circ} \mathrm{C}$ under argon atmosphere, then neutralized with a HCl-solution (2 M) and extracted with dichloromethane. The combined organic layers were washed with a saturated $\mathrm{NaHCO}_{3}$ solution, with brine and dried over $\mathrm{MgSO}_{4}$. The solvents were removed and the crude compound was purified by column chromatography (silicagel; eluent: ethylacetate) and collected as a yellow oil.

Yield $=5.7 \mathrm{~g}(68 \%)(2$ steps $)$

$[\alpha]_{D}^{25}=+111 \mathrm{deg} \cdot \mathrm{dm}^{-1} \cdot \mathrm{mol}^{-1} \cdot 1 \quad\left(\mathrm{c}=0.5\right.$ in $\left.\mathrm{CH}_{2} \mathrm{Cl}_{2}\right)$

${ }^{1} \mathrm{H}-\mathrm{NMR}\left(\mathrm{CDCl}_{3}\right): \quad \delta=8.06(\mathrm{~d}, \mathrm{~J}=1.5 \mathrm{~Hz}, 2 \mathrm{H}), 7.93(\mathrm{~d}, 2 \mathrm{H}), 7.38(\mathrm{~d}, 2 \mathrm{H}), 7.34(\mathrm{dd}, 2 \mathrm{H})$, $7.04(\mathrm{~d}, 2 \mathrm{H}), 5.18(\mathrm{~s}, 2 \mathrm{H}), 3.11(\mathrm{~s}, 2 \mathrm{H})$.

${ }^{13} \mathrm{C}-\mathrm{NMR}\left(\mathrm{CDCl}_{3}\right): \quad \delta=151.2,132.5,129.8,128.7,128.1,127.4,123.8,116.6,114.7,113.8$, 83.2, 75.7 .

$\mathrm{MS}: m / z=334\left(\mathrm{M}^{+}\right)$

$\mathrm{C}_{24} \mathrm{H}_{14} \mathrm{O}_{2}$ 334.4: Calcd. C 86.21, H 4.22; Found C 85.66, H 4.03

Synthesis of (S)-(+)-6,6'-diethynyl-2'-hexyloxy-[1,1'-binaphthalene]-2-ol 6

(S)-(-)-6,6'-dibromo-2'-hexyloxy-[1,1'-binaphthalene]-2-ol 4

Under argon atmosphere a solution of $\mathbf{1}(14.4 \mathrm{~g}, 32.4 \mathrm{mmol})$, dissolved in dry DMF (70 ml), was slowly added to a suspension of $\mathrm{NaH}(0.78 \mathrm{~g}, 32.4 \mathrm{mmol})$ in dry DMF (30 ml). After 15 minutes, hexylbromide (4.6 ml, $32.4 \mathrm{mmol})$ and anhydrous NaI (100 mg) was added. The 
mixture was stirred overnight at $50{ }^{\circ} \mathrm{C}$. After cooling, the mixture was poured into water (200 ml) and extracted with dichloromethane. The organic layer was washed with a saturated $\mathrm{NaHCO}_{3}$-solution and with brine and dried over $\mathrm{MgSO}_{4}$. After removal of the solvents, the crude compound was purified by column chromatography (silicagel; eluent: hexane/dichloromethane $(60: 40 \mathrm{v} / \mathrm{v}))$ and isolated as an oil.

Yield : $8.2 \mathrm{~g}(48 \%)$

$[\alpha]_{D}^{25}=+32.4 \mathrm{deg} \cdot \mathrm{dm}^{-1} \cdot \mathrm{mol}^{-1} \cdot 1 \quad\left(\mathrm{c}=0.06\right.$ in $\left.\mathrm{CHCl}_{3}\right)$

${ }^{1} \mathrm{H}-\mathrm{NMR}\left(\mathrm{CDCl}_{3}\right): \quad \delta=8.05(\mathrm{~d}, \mathrm{~J}=1.5 \mathrm{~Hz}, 1 \mathrm{H}), 8.00(\mathrm{~d}, \mathrm{~J}=1.5 \mathrm{~Hz}, 1 \mathrm{H}), 7.93(\mathrm{~d}, 1 \mathrm{H}), 7.80$ $(\mathrm{d}, 1 \mathrm{H}), 7.46(\mathrm{~d}, 1 \mathrm{H}), 7.34(\mathrm{~d}, 1 \mathrm{H}), 7.34(\mathrm{dd}, 1 \mathrm{H}), 7.28(\mathrm{dd}, 1 \mathrm{H}), 7.02(\mathrm{~d}, 1 \mathrm{H}), 6.86(\mathrm{~d}, 1 \mathrm{H})$, $4.89(\mathrm{~d}, 1 \mathrm{H}), 3.99(\mathrm{~m}, 2 \mathrm{H}), 1.43(\mathrm{qu}, 2 \mathrm{H}), 1.01(\mathrm{~m}, 6 \mathrm{H}), 0.75(\mathrm{t}, 3 \mathrm{H})$.

(S)-6,6'-di(trimethylsilylethynyl)-2'-hexyloxy-[1,1'-binaphthalene]-2-ol 5

The procedure, described for $\mathbf{2}$, was followed, starting from of $\mathbf{3}(5.28 \mathrm{~g}, 10.0 \mathrm{mmol})$. The compound was purified by column chromatography (silica; eluent: ethylacetate/hexane (10:90 $\mathrm{v} / \mathrm{v})$ ) and isolated as an oil.

${ }^{1} \mathrm{H}-\mathrm{NMR}\left(\mathrm{CDCl}_{3}\right): \quad \delta=8.03(\mathrm{~d}, \mathrm{~J}=1.5 \mathrm{~Hz}, 1 \mathrm{H}), 8.00(\mathrm{~d}, \mathrm{~J}=1.5 \mathrm{~Hz}, 1 \mathrm{H}), 7.94(\mathrm{~d}, 1 \mathrm{H}), 7.82$ (d, 1H), $7.42(\mathrm{~d}, 1 \mathrm{H}), 7.32(\mathrm{~d}, 1 \mathrm{H}), 7.28(\mathrm{dd}, 1 \mathrm{H}), 7.21(\mathrm{dd}, 1 \mathrm{H}), 7.06(\mathrm{~d}, 1 \mathrm{H}), 6.90(\mathrm{~d}, 1 \mathrm{H})$, $4.97(\mathrm{~s}, 1 \mathrm{H}), 3.97(\mathrm{~m}, 2 \mathrm{H}), 1.43(\mathrm{~m}, 2 \mathrm{H}), 1.0(\mathrm{~m}, 6 \mathrm{H}), 0.75(\mathrm{t}, 3 \mathrm{H}), 0.26(\mathrm{~s}, 18 \mathrm{H})$.

(S)-(+)-6,6'-diëthynyl-2'-hexyloxy-[1,1'-binaphthalene]-2-ol 6

The procedure, described for $\mathbf{3}$, was followed, starting from $\mathbf{5}$. The compound was purified twice by column chromatography (silica; eluent: ethylacetate/hexane (first: 20:80 v/v, second time:10:90 v/v) and isolated as an oil.

Yield $=3.0 \mathrm{~g}(71 \%)(2$ steps $)$

$[\alpha]_{D}^{25}=+32.0 \mathrm{deg} \cdot \mathrm{dm}^{-1} \cdot \mathrm{mol}^{-1} \cdot 1 \quad\left(\mathrm{c}=1.0\right.$ in $\left.\mathrm{CH}_{2} \mathrm{Cl}_{2}\right)$ 
${ }^{1} \mathrm{H}-\mathrm{NMR}\left(\mathrm{CDCl}_{3}\right): \quad \delta=8.05(\mathrm{~d}, \mathrm{~J}=1.5 \mathrm{~Hz}, 1 \mathrm{H}), 8.00(\mathrm{~d}, \mathrm{~J}=1.5 \mathrm{~Hz}, 1 \mathrm{H}), 7.96(\mathrm{~d}, 1 \mathrm{H}), 7.82$ (d, 1H), $7.44(\mathrm{~d}, 1 \mathrm{H}), 7.32(\mathrm{~d}, 1 \mathrm{H}), 7.29(\mathrm{dd}, 1 \mathrm{H}), 7.21(\mathrm{dd}, 1 \mathrm{H}), 7.08(\mathrm{~d}, 1 \mathrm{H}), 6.92(\mathrm{~d}, 1 \mathrm{H})$, $4.94(\mathrm{~s}, 1 \mathrm{H}), 3.93(\mathrm{~m}, 2 \mathrm{H}), 3.09(\mathrm{~s}, 1 \mathrm{H}), 3.05(\mathrm{~s}, 1 \mathrm{H}), 1.43(\mathrm{~m}, 2 \mathrm{H}), 1.0(\mathrm{~m}, 6 \mathrm{H}), 0.75(\mathrm{t}, 3 \mathrm{H})$. ${ }^{13} \mathrm{C}-\mathrm{NMR}\left(\mathrm{CDCl}_{3}\right): \quad \delta=155.3,151.2,132.7,132.5,131.5,129.8,128.9,128.7,128.1,127.6$, $127.4,123.9,123.8,117.3,116.6,115.6,114.7,114.6,113.9,83.2,82.8,75.7,75.6,68.4$, $30.1,28.0,24.1,21.3,12.8$.

MS: $m / z=418\left(\mathrm{M}^{+}\right), 334\left(\mathrm{M}^{+}-\mathrm{C}_{6} \mathrm{H}_{12}\right)$

$\mathrm{C}_{30} \mathrm{H}_{26} \mathrm{O}_{2} 418.53$ Calcd. C 86.09 H 6.26; Found C 85.78, H 6.12

Polymer synthesis

A general procedure was as follows: a solution of $7(2.50 \mathrm{mmol}), \mathrm{Pd}\left[\mathrm{PPh}_{3}\right]_{2} \mathrm{Cl}_{2}(25.0 \mathrm{mg})$ and of $\mathrm{PPh}_{3}(50.0 \mathrm{mg})$, dissolved in freshly distilled piperidine $(10 \mathrm{ml})$ and dry THF $(5 \mathrm{ml})$, was purged with argon and heated to $40{ }^{\circ} \mathrm{C}$. A purged solution of 3 / 6 (2.50 mmol) in dry THF (10 ml) was added, followed by a purged solution of of $\mathrm{CuI}(2.0 \mathrm{mg})$ and $\mathrm{LiBr}(10.0 \mathrm{mg})$ in dry THF (10 ml). The reaction mixture was stirred for two days under reflux and inert atmosphere. After cooling, THF was added and the polymer was precipitated in methanol. The polymer was filtered, redissolved and reprecipitated. This procedure was repeated three times. Finally, the isolated polymer was dried under reduced pressure.

In case of ppol I, the reaction mixture was not diluted with THF, neither was the polymer afterwards dissolved in THF, but DMF was used instead.

\section{ppol I :}

Yield: $1.7 \mathrm{~g}(95 \%)$

${ }^{1} \mathrm{H}-\mathrm{NMR}\left(\mathrm{CDCl}_{3}\right): \quad \delta=7.80(\mathrm{~s}(\mathrm{br}), 2 \mathrm{H}), 7.74(\mathrm{~d}, 2 \mathrm{H}), 7.18(\mathrm{~d}, 2 \mathrm{H}), 7.16(\mathrm{dd}, 2 \mathrm{H}), 6.95(\mathrm{~s}$, 2H), $6.94(\mathrm{~d}, 2 \mathrm{H}), 5.41(\mathrm{~s}, 2 \mathrm{H}), 3.93(\mathrm{t}, 4 \mathrm{H}), 1.82(\mathrm{~m}, 4 \mathrm{H}), 1.35(\mathrm{~m}, 4 \mathrm{H}), 1.20(\mathrm{~m}, 8 \mathrm{H}), 0.76(\mathrm{t}$, $6 \mathrm{H})$.

ppol II : 
Yield: $2.3 \mathrm{~g}(86 \%)$

${ }^{1} \mathrm{H}-\mathrm{NMR}\left(\mathrm{CDCl}_{3}\right): \quad \delta=8.09(\mathrm{~d}, \mathrm{~J}=1.5 \mathrm{~Hz}, 1 \mathrm{H}), 8.06(\mathrm{~d}, \mathrm{~J}=1.5 \mathrm{~Hz}, 1 \mathrm{H}), 7.98(\mathrm{~d}, 1 \mathrm{H}), 7.86$

$(\mathrm{d}, 1 \mathrm{H}), 7.46(\mathrm{~d}, 1 \mathrm{H}), 7.38(\mathrm{~d}, 1 \mathrm{H}), 7.33(\mathrm{dd}, 1 \mathrm{H}), 7.29(\mathrm{dd}, 1 \mathrm{H}), 7.14(\mathrm{~d}, 1 \mathrm{H}), 7.03(\mathrm{~s}, 2 \mathrm{H})$,

$7.00(\mathrm{~d}, 1 \mathrm{H}), 5.00(\mathrm{~s}, 1 \mathrm{H}), 3.9(\mathrm{~m}, 6 \mathrm{H}), 1.82(\mathrm{~m}, 4 \mathrm{H}), 0.9-1.6(\mathrm{~m}, 20 \mathrm{H}), 0.86(\mathrm{t}, 6 \mathrm{H}), 0.75(\mathrm{t}$, $3 \mathrm{H})$.

\section{Functionalization $^{[5]}$}

A general procedure is as follows: Prior to reaction, the chromophore was recrystallized from ethanol and all reagents and solvents were thoroughly dried. ppol I-II $(0.333 \mathrm{mmol}$ of naphthol groups $)$, chromophore $(0.400 \mathrm{mmol})$ and $\mathrm{PPh}_{3}(0.666 \mathrm{mmol})$ were dissolved in dry THF (15 ml). The mixture was purged with argon and DEAD (diethylazodicarboxylate) (0.666 mmol) was injected. The reaction vessel was sealed and the mixture was stirred for two days at room temperature. Then, the polymer was isolated by precipitation in methanol, collected by filtration and dried. For purification, the polymer was redissolved in THF and precipitated in methanol. This procedure was repeated until the filtrate was only slightly coloured. Finally, the isolated polymer was dried under reduced pressure.

\section{Measurements}

1D ${ }^{1} \mathrm{H}-\mathrm{NMR}(300 \mathrm{MHz})$ and ${ }^{13} \mathrm{C}-\mathrm{NMR}(75 \mathrm{MHz})$ measurements were carried out on a Bruker Avance $300 \mathrm{MHz}$; NOESY and ROESY experiments were done on a Bruker AMX 400MHz apparatus. The number average molecular weights $\left(\bar{M}_{n}\right)$ and polydispersity $\left(\bar{M}_{w} / \bar{M}_{n}\right)$ were measured by gel permeation chromatography (GPC) with a Waters HP-GPC with a tuneable absorbency detector and a differential refractometer, using THF as an eluent towards polystyrene standards. The UV-VIS spectra were recorded on a Varian Cary 400. Glass transition temperatures of the polymers and chromophores were determined by differential scanning calorimetry (DSC) on a DCS 7 from Perkin Elmer with a heating rate of $50{ }^{\circ} \mathrm{C} / \mathrm{min}$. Optical rotations were measured with an Analis Optical Activity Polaar 20 apparatus. 


\section{Results and discussion}

In this paper, eight new chromophore-functionalized, chiral, helical polymers were synthesized for nonlinear optical applications. As stated earlier, these polymers were obtained by functionalization of precursor polymers, since the direct polymerization of chromophore-functionalized monomers using the Sonogashira reaction leads to chromophore degradation. Therefore, two precursor polymers, with a different number of naphthol groups per binaphthalene unit (one or two) were synthesized. The number of naphthol groups per binaphthalene unit was varied, since the two naphthol groups in a binaphthalene unit point in the opposite direction. Therefore, when both naphthol groups are functionalized with chromophores, the two chromophores will point in an opposite direction as well. This would result in a quasi centrosymmetrical ordering, which makes high second-order NLO responses impossible. As a consequence, systematically blocking one of the two naphthol groups with an alkyl group, can increase the NLO response.

The precursor polymers were functionalized with alcohol-functionalized chromophores by means of a Mitsunobu reaction. Therefore, four alcohol-functionalized chromophores were used. The chromophores differ in the chromophore nature and in their spacer length. One can argue that in case of shorter, more rigid spacers, the backbone tends to impose its chiral ordering more efficiently to the chromophores, which may benefit the NLO response.

The synthesis of the monomers $\mathbf{3}$ and $\mathbf{6}$ is straightforward, starting from $\mathbf{1}$ (scheme 1). The key reaction is the introduction of the acetylene groups, which was performed by a Sonogashira reaction. A second Sonogashira reaction with $\mathbf{3}$ or $\mathbf{6}$ and the diiodo compound $\mathbf{7}$ resulted in the formation of the precursor polymers ppol I and ppol II (scheme 2). The chromophores could be linked to the polymer backbone of the precursor polymers ppol I and ppol II under Mitsunobu conditions. Since this reaction proceeds under very mild reaction 
conditions, it should be possible to use a great variety of chromophores. The functionalization is schematically shown for ppol II in scheme 3.

The physical properties of the polymers are listed in Table 1. The degree of functionalization (DF) is defined as the mole percentage of naphthol groups that are successfully substituted by chromophores and was determined by UV-VIS spectroscopy. The molecular weights and polydispersities were measured by GPC towards polystyrene standards. Molecular weights measured this way are rather underestimated; the real values may be estimated about 2 times larger ${ }^{[4 \mathrm{~d}]}$.

The glass transition temperatures are determined by DSC. No $\mathrm{T}_{\mathrm{g}}$ was observed for the precursor polymers, while the chromophore-functionalized polymers showed a very clear $\mathrm{T}_{\mathrm{g}}$. We assume that the observed $\mathrm{T}_{\mathrm{g}}$ in the chromophore-functionalized polymers is the weakening of the chromophores in the polymer and not the weakening of the whole polymer material. Indeed, DSC measurements indicate that the $\mathrm{T}_{\mathrm{g}}$ of the chromophores are $46{ }^{\circ} \mathrm{C}(\mathbf{C})$ and $16{ }^{\circ} \mathrm{C}(\mathbf{D})$ (heating rate $=30^{\circ} \mathrm{C} / \mathrm{min}$ ); $\mathbf{A}$ and $\mathbf{B}$ couldn't be made amorphous. Linking chromophores to the rigid, rod-like backbone reduces the mobility of the chromophores and consequently increases the $\mathrm{T}_{\mathrm{g}}$.

The optical rotations are quite high and increase dramatically when chromophores, whose $\lambda_{\max }$ is close to the applied wavelength, are introduced. This suggests ${ }^{[1 \mathrm{~d}-\mathrm{e}]}$ that the chiral helical polymer backbone imposes its chiral ordering to the chromophores, which was confirmed by $\mathrm{CD}$ experiments.

Finally, we have tried to determine the orientation of the chromophores with respect to the polymer backbone, using 2D NMR spectroscopy. In a NOESY experiment, crosspeaks between the chromophore unit and the polymer backbone are observed in pol I-A, as presented in Figure 1. This is a clear evidence that the chromophores are located close to the polymer backbone and that they don't point away. Such cross-peaks were not observed in pol 
I-B, neither with NOESY, nor with related ROESY-experiments. Probably, the longer alkylspacer between the chromophore and the polymer backbone reduces the orientation of the chromophore by the helical backbone.

Preliminary SHG measurements $\left(\lambda_{\text {source }}=1064 \mathrm{~nm}\right)$ of corona-poled films of pol I-C and pol I-D show a moderate NLO response $\left(\chi_{z z z}^{(2)}=12 \mathrm{pm} / \mathrm{V}\right.$ and $24 \mathrm{pm} / \mathrm{V}$ respectively $)$. Further work will be done to get a better insight in the role of chirality in the second-order NLO.

\section{Conclusions}

We have demonstrated the synthesis of chiral, chromophore-functionalized helical polybinaphthalenes with acetylenic linkages. It was stated that chromophore-functionalized binaphthalene monomers do not resist the Sonogashira reaction. Therefore, the polymers were prepared in a two-step process, in which precursor polymers with either one or two naphthol groups per binaphthalene unit were transformed with alcohol-functionalized chromophores into their chromophore-functionalized polymers via a Mitsunobu reaction. CD experiments suggest the chiral ordering of the chromophores. NOESY experiments indicated that at least in some polymers, the chromophores are close to the polymer backbone. This work contributes in the further development of new polymer materials for nonlinear optics and photonics.

\section{Acknowledgements}

We are very grateful to KVH Industries, Inc., Middletown, RI, U.S.A. for their financial support. This work was also supported by the Fund for Scientific Research-Flanders (FWOVlaanderen, G.0308.96) and from the Katholieke Universiteit Leuven (GOA/2000/03). G.K. is a doctoral fellow of the Fund for Scientific Research.

\section{References}

[1] [1a] T. Verbiest, C. Samyn, C. Boutton, S. Houbrechts, M. Kauranen, A. Persoons, Adv.

Mater. 1996, 8, 756; [1b] M. M. Bouman, E. E. Havinga, R. A. J. Janssen, E. W. Meijer, Mol. 
Cryst. Liq. Cryst. 1994, 256, 439; [1c] M. N. Teerenstra, J. G. Hagting, G. T. Oostergetel, A. J. Schouten, M. A. C. Devillers, R. J. M. Nolte, Thin Solid Films 1994, 248, 110; [1d] G. Koeckelberghs, M. Van Beylen, C. Samyn, Materials Science and Engineering C 2001, 18, 15; [1e] G. Koeckelberghs, M. Van Beylen, C. Samyn, Eur. Pol. J. 2001, 371991 [1f] L. Ma, Q.-S. Hu, D. Vitharana, L. Pu, Polymer Preprints 1996, 37, 462; [1g] L. Ma, Q.-S. Hu, D. Vitharana, C. Wu, C. M. S. Kwan, L. Pu, Macromolecules 1997, 30, 204

[2] [2a] T. Verbiest, M. Kauranen, A. Persoons, J. Mater. Chem. 1999, 9, 2005; [2b] M. Kauranen, T. Verbiest, A. Persoons, J. Nonlinear Opt. Phys. 1999, 8, 171

[3] [3a] G. D. Y. Sogak, D. J. Cram, J. Am. Chem. Soc. 1979, 101, 3035; [3b] Z. Bao, Y.

Chen, R. Cai, L. Yu, Macromolecules 1993, 26, 5281; [3c] S. Ermer, S. M. Lovejoy, D. S.

Leung, H. Warren, C. R. Moylan, R. J. Twieg, Chem. Mater. 1997, 9, 1437

[4] For a selection of modi operandi for the Sonogashira reaction, see: [4a] L. Brandsma, S. F. Vasilevsky, H. D. Verkruijsse “Application of Transition Metal Catalysts in Organic Synthesis" Springer-Verlag, Berlin, Heidelberg, New York 1998; [4b] A. P. Melissaris, M. H. Litt, J. Org. Chem. 1992, 57, 6998 ; [4c] A. P. Melissaris, M. H. Litt, J. Org. Chem. 1994, 59, 5818; [4d] S. Takahashi, Y. Kuroyama, K. Sonogashira, N. Hagihara, Synthesis 1980, 627; [4e] L. Ma, Q.-S. Hu, K. Y. Musick, D. Vitharana, C. Wu, C. M. S. Kwan, L. Pu, Macromolecules 1996, 29, 5083

[5] O. Mitsunobu, Synthesis 1981, 1

\section{Captions to figures and schemes}

Figure 1: NOESY-spectrum of pol I-A

Scheme 1: Synthesis of binaphthalene monomers 3 and 6

Scheme 2: Synthesis of the precursor polymers

Scheme 3: Functionalization of the precursor polymers

Scheme 4: Structure of the chromophores 
Table 1: Physical properties of the polymers

\begin{tabular}{c|ccccc}
\hline Polymer & $\begin{array}{c}\mathrm{DF} / \\
\%\end{array}$ & $\begin{array}{c}\bar{M}_{n} / \\
10^{3} \mathrm{~g} \mathrm{~mol}^{-1}\end{array}$ & $\begin{array}{c}T_{g} / \\
{[\alpha]_{D}^{20} /}\end{array}$ & $\begin{array}{c}{ }^{\circ} \mathrm{C} \\
10^{-2} \mathrm{deg} \cdot \mathrm{dm}^{-1} \cdot \mathrm{g}^{-1} \cdot \mathrm{ml} \\
\left(\mathrm{c} / 10^{-2} \mathrm{~g} \cdot \mathrm{ml}^{-1}\right)\end{array}$ \\
\hline ppol I & & 5.4 & 2.6 & $*$ & $5.2(0.040)$ \\
ppol II & & 2.3 & 2.3 & $*$ & $3.8(0.056)$ \\
pol I-A & 65 & 8.2 & 2.2 & 140 & $2.6(0.025)$ \\
pol I-B & 50 & 11 & 1.8 & 100 & $5.1(0.025)$ \\
pol I-C & 50 & 11 & 1.9 & 168 & $70(0.025)$ \\
pol I-D & 65 & 14 & 1.6 & 135 & $67(0.025)$ \\
pol II-A & 45 & 2.8 & 2.1 & 78 & $3.9(0.010)$ \\
pol II-B & 10 & 2.3 & 2.4 & 71 & $4.2(0.024)$ \\
pol II-C & 65 & 3.9 & 1.9 & 105 & $160(0.009)$ \\
pol II-D & 80 & 4.4 & 1.9 & 89 & $146(0.010)$ \\
\hline
\end{tabular}

* no $T_{g}$ observed between $0-250{ }^{\circ} \mathrm{C}$

$\mathrm{DF}=$ degree of functionalization 